\title{
Cloacogenic polyp: a rare type of polyp
}

A cloacogenic polyp is a rare type of benign lesion that is part of mucosal prolapse syndrome [1]. Mucosal prolapse syndrome encompasses entities such as solitary rectal ulcer syndrome, gastric antral vascular ectasia, inflammatory cap polyp, prolapsing mucosal polyp, and the cloacogenic polyp [2], whose common etiology has been proposed to be mucosal prolapse [3]. Cloacogenic polyps are between 1 and $5 \mathrm{~cm}$, and are usually sessile but can be pedunculated [3]. Usually located at the anorectal junction, they can be found in the colon. A cloacogenic polyp can be asymptomatic or responsible for hematochezia [4]. It is a benign lesion, but some cases of adenocarcinoma arising from cloacogenic polyps have been described [5].

Here we describe two cases of patients with cloacogenic polyps ( $\triangleright$ Video 1 ). The first case is a 38-year-old woman who underwent a colonoscopy for abdominal pain, hematochezia, and mucus in the stool. In the sigmoid colon, there was a pedunculated inflammatory lesion with a 20-mm head and some area of irregular pit pattern (Kudo $V n$ ) on narrow-band imaging ( $\mathbf{F i g . 1}$ ). It was resected en bloc with a hot snare. The second case is a 71-year-old woman with hematochezia. A similar lesion with a $30-\mathrm{mm}$ red head was found in the sigmoid colon. Dilation of lymphatic vessels was present on the stalk of the polyp. Endoscopic submucosal dissection with the tip of a snare allowed en bloc resection ( $\triangleright$ Fig. 2).

For both lesions, pathology reports showed an ulcerated surface with dilated colonic glands within an inflammatory stroma and significant hemorrhagic suffusion. The glands were dilated, sometimes cystic, and filled with mucopurulent material. The mucosa adjacent to the stalk of the polyp was normal. There was no sign of malignancy or dysplasia ( Fig.3). These observations were consistent with a cloacogenic polyp.
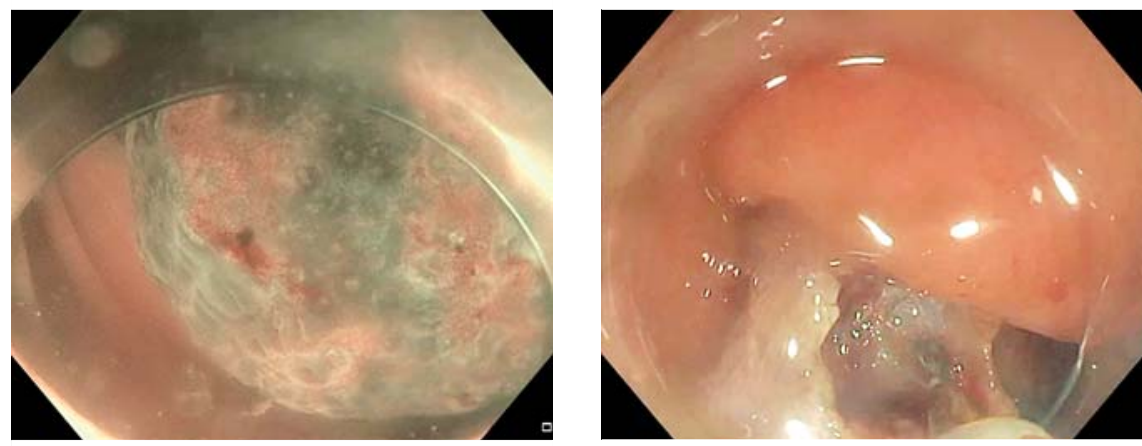

- Fig. 1 A pedunculated inflammatory polyp in the sigmoid colon with a $20-\mathrm{mm}$ head and some area of irregular pit pattern (Kudo $\mathrm{Vn}$ ) on narrow band imaging.

- Fig. 2 Endoscopic submucosal dissection with the tip of a snare of the inflammatory lesion.

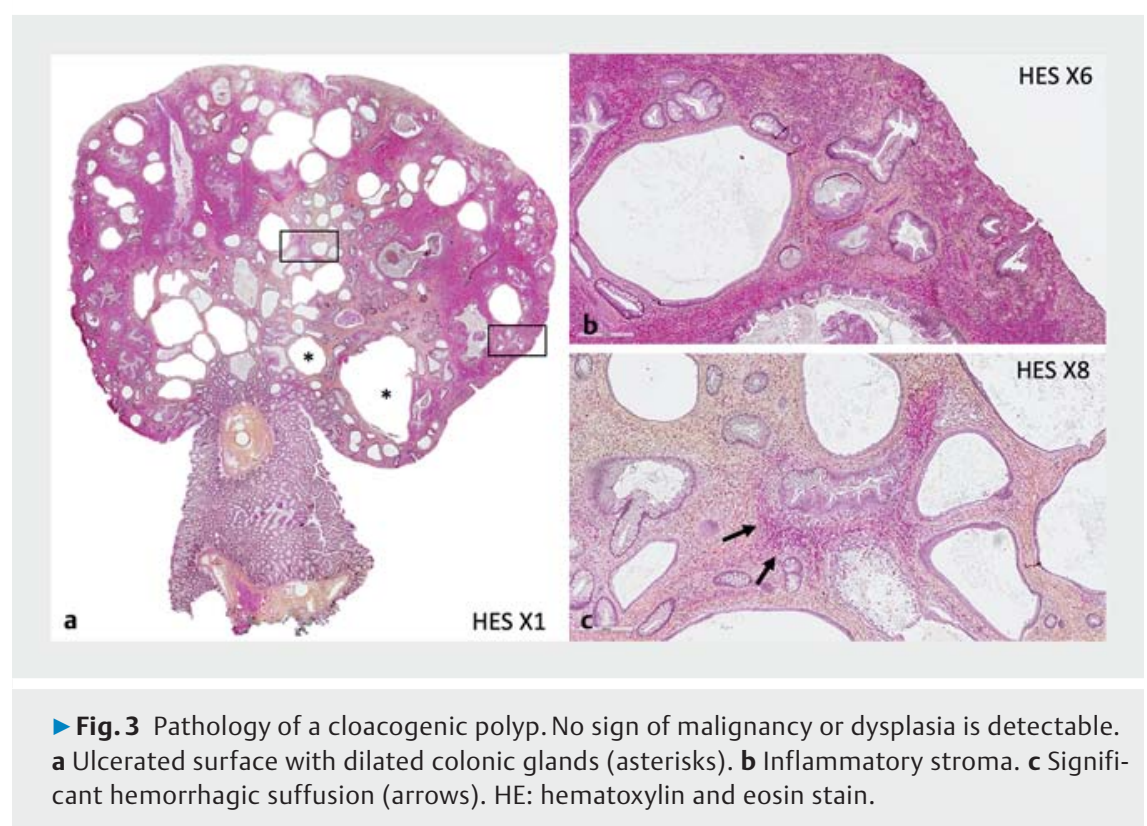

These cases highlight a rarely described lesion of the colon that should be known by endoscopists.

Endoscopy_UCTN_Code_TTT_1AQ_2A]

\section{Competing interests}

The authors declare that they have no conflict of interest.
The authors

Thomas Lambin ${ }^{1,2}$, Pierre-Marie Lavrut ${ }^{3}$, Pierre Lafeuille ${ }^{1}$, Jérôme Rivory ${ }^{1}$, Florian Rostain ${ }^{1}$, Paul Bonniaud ${ }^{1}$, Mathieu Pioche ${ }^{1,2}$

1 Gastroenterology and Endoscopy Unit, Pavillon L, Edouard Herriot Hospital, Lyon, France

2 Inserm U1032, LabTAU, Lyon, France

3 Pathology Institute of Hospices Civils de Lyon, Groupement Hospitalier Est, University Hospital of Lyon, Bron 


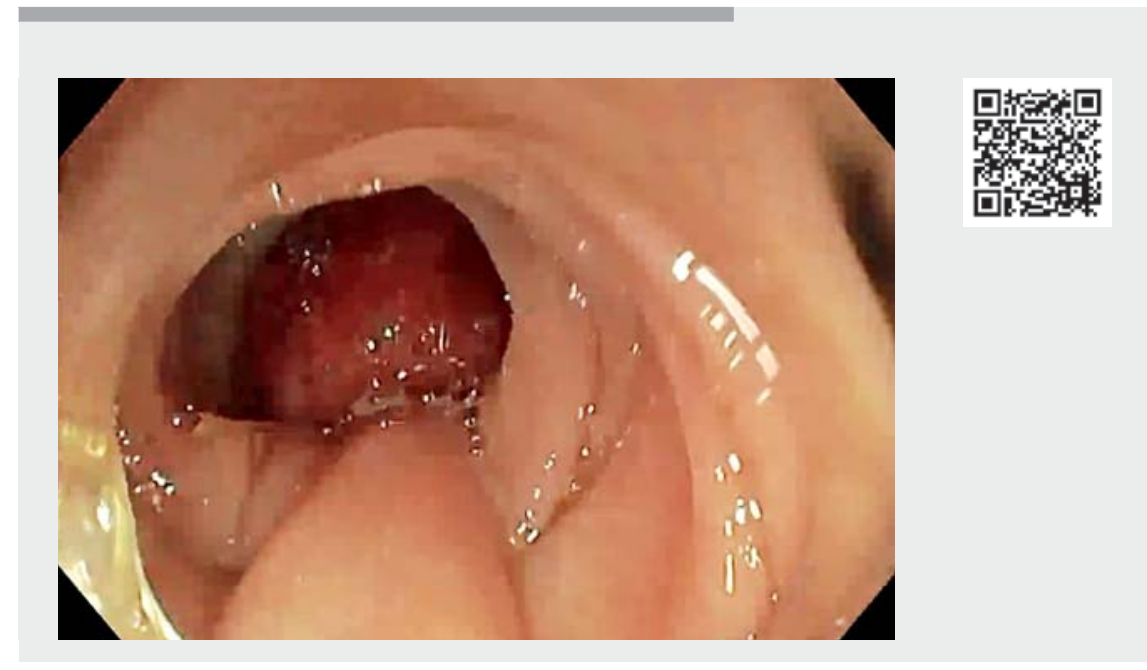

$\checkmark$ Video 1 Cloacogenic polyp: a rare type of polyp.

Corresponding author

\section{Thomas Lambin, MD}

Endoscopy Unit - Digestive Disease Department, Pavillon L - Edouard Herriot Hospital, 69437 Lyon CEDEX, France thomaslambin@hotmail.fr

\section{References}

[1] du Boulay CE, Fairbrother ], Isaacson PG. Mucosal prolapse syndrome - a unifying concept for solitary ulcer syndrome and related disorders. J Clin Pathol 1983; 36: 1264-1268

[2] Tendler DA, Aboudola S, Zacks JF et al. Prolapsing mucosal polyps: an underrecognized

\section{Bibliography}

Endoscopy 2022; 54: E117-E118

DOI 10.1055/a-1408-0585

ISSN 0013-726X

published online 30.3 .2021

(c) 2021. Thieme. All rights reserved.

Georg Thieme Verlag KG, Rüdigerstraße 14, 70469 Stuttgart, Germany

\section{ENDOSCOPY E-VIDEOS}

https://eref.thieme.de/e-videos

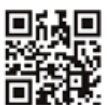

Endoscopy E-Videos is an open access online section, reporting on interesting cases and new techniques in gastroenterological endoscopy. All papers include a high quality video and all contributions are freely accessible online. Processing charges apply (currently EUR 375), discounts and wavers acc. to HINARI are available.

This section has its own submission website at https://mc.manuscriptcentral.com/e-videos 